\title{
Equal pay for all: an idea whose time has not, and will not, come (PENULTIMATE DRAFT)
}

\author{
Thomas Mulligan
}

My task in this essay is to evaluate an idea: giving each person, regardless of profession or indeed whether he or she works or not, equal pay. I shall call this the equal pay idea, or EPI.

We are to imagine an economy of $X$ persons which generates (post-redistribution) $\$ Y$ in national income (say, yearly). EPI, as I understand it, prescribes that each person receives $\$(Y / X)$. Under EPI, distinctions often thought to matter for economic or moral reasons are ignored. Everyone receives the same pay: doctors and mechanics; the lazy and the sedulous; those for whom $\$(Y / X)$ is a bounty and those who cannot survive on it.

Such an economy will require redistribution. EPI's desired, hyper-egalitarian pattern of distribution will not (generally) arise via market forces. Among other things, a (wellfunctioning) market does not pay someone if doing so does not entice her or him to work or otherwise contribute to production. ${ }^{1}$ But if EPI were in operation, we would doubtless encounter people who chose to not work - likely many of them - yet they would still receive $\$(Y / X)$. So there must be a government to produce the income distribution EPI demands.

EPI is an ambiguous idea, and I shall discuss some of these ambiguities shortly. For example, suppose that in Year 1 Jack consumes his entire share while Denise consumes half of hers and invests the other half. In Year 2, Denise's investments produce $\$ Z$ in income. Is Denise alone entitled to that $\$ Z$ ? Or does she only get $\$(Z / X)$ ? It is important to clear up questions like these - to make EPI reasonably precise - if we wish to subject it to economic and moral analysis.

We shall see that EPI, even when construed in its most attractive form, falls short - and badly. This is for two reasons. First, EPI is inefficient. It would remove nearly all incentive to work, shrink national income, and leave all citizens badly-off - albeit equally badly-off.

Second, EPI offends our sense of justice. I conclude this paper by briefly describing the empirical literature on justice, which suggests that human beings across lines of race, gender, socioeconomic class, and culture would reject EPI. Indeed, we reject more modest egalitarian distributive rules.

EPI has not attracted support even among philosophers and economists with strong egalitarian sentiments. This is for good reasons, which I shall explain. I note, however, that a form of EPI has been defended by Joseph Carens (1981), and I recommend that work to readers interested in a defense of the idea. 


\section{What, exactly, is EPI?}

EPI should not be confused with a universal basic income (UBI). (See Zwolinski, Ch. 6 in this volume; Cooke, Ch. 7 in this volume. The purpose of UBI is to supplement labor market earnings (if any), not replace them. Now, UBI is intended to replace elements of extant welfare systems, and for that reason (among others) I oppose it (see Mulligan 2018b). I do, however, concede that UBI is a far more attractive prospect than EPI is.

The first point to clarify about EPI is the status of benefits like health insurance and employer contributions to retirement. These are increasingly important parts of compensation in contemporary economies, and EPI would seemingly ignore them. That is, even if each citizen received $\$(Y / X)$ in income, those who worked might well receive enormous benefits packages from their employers, undermining EPI's egalitarian goal.

Similarly, there are non-pecuniary benefits and costs which would be important to incorporate into EPI. Some jobs - copyediting, say - offer flexible hours and working location. Other jobs, like hauling trash, are arduous. Markets price these benefits and costs into wages in the form of compensating differentials - the copyeditor receives less than he or she otherwise would because of the job's non-pecuniary benefits; garbagemen are paid more because of the non-pecuniary costs. (See Brouwer and van der Deijl, Ch. 4 in this volume.) The proper index for EPI would seem to be total compensation, including pecuniary and non-pecuniary benefits and costs.

Next, we consider the question of investment income raised in the introduction. After each person receives his or her share, $\$(Y / X)$, some will choose to invest a portion of it rather than consume it in its entirety. Those investments will generate income which would, without intervention, create inequality. The question is whether that inequality is of the type EPI is intended to prevent.

I think not. For one thing, the proposal is for "equal pay", not "equal income" simpliciter - suggesting that the concern is labor's share of income only. ${ }^{2}$ Moreover, if EPI extended to capital income as well there would be almost no incentive to invest, and thus almost no investment. This would be a catastrophe for economic growth.

Then there is a question of scope. It cannot simply be that each person is entitled to a share, $\$(Y / X)$, because that would provide shares to infants, who cannot make use of them. This and similar cases (e.g. people in comas) raise non-trivial questions: are these people simply exempted? Does an infant's share go to his or her parents? If so, must the parents spend it entirely altruistically, on the child? Or are the shares held in trust, so that upon reaching the age of majority (say, 18), a person receives $\$\left(Y_{0} / X_{0}+Y_{1} / X_{1}+Y_{2} / X_{2}+\ldots+\right.$ $Y_{17}\left(X_{17}\right)$ ?

EPI provides a share to those who do not work - but what about non-citizens? People who are in the country illegally? Criminals? We can wave aside these complexities, assuming that consensus has been reached about EPI's scope, but in fact I think these questions would spark hot debate.

Finally, it is difficult to evaluate a pay proposal like this without context on the welfare programs which would operate alongside it. Extant welfare programs are not typically motivated by considerations of equality but of need. That is, these programs focus on 
needy groups like children and the elderly. (Of course, these programs may have the incidental effect of making the distribution of income more equal.)

Now, if EPI is to replace welfare programs, then I cannot see who would support it. It could not possibly be generous enough to provide even minimal support to, say, poor families with dependent children. This is a fatal flaw for UBI, in my opinion, and for EPI the problem would be worse.

Thus, we are driven to suppose that EPI is intended to operate alongside a suitable welfare system. However, this itself is impossible, because the disincentive effects of EPI would preclude raising sufficient revenue to support a welfare system, for reasons I shall now describe.

\section{On the inefficiency of EPI}

One fatal problem with EPI, albeit not the only one, is that it is "inefficient". We might say, correctly, that EPI would make us poor, collectively and as individuals. But that is inadequate; the idea should be made precise. That is the main task for this section.

We begin with an example. Suppose that Justin and Rachael wish to travel from Philadelphia to Providence by train. We may measure the benefit that this trip provides them by reference to their reservation prices - the maximum amount that they are willing to pay to take the trip. If the market price of a ticket is less than their reservation prices, they will, by definition, buy tickets. If it is more, they will not. If they do buy tickets, the difference between their reservation prices and the market price provides a measure of this trip's economic benefit to them.

Suppose that Justin's reservation price is $\$ 120$ - he will pay up to this amount for a ticket, and no more - and Rachael's is $\$ 100$. Suppose, further, that the prevailing price of a Philadelphia-Providence ticket is $\$ 90$. This is what the train company receives for each ticket. What economic value is created by this market of two consumers, if any?

We calculate as above: Justin would pay up to $\$ 120$ but only needs to pay $\$ 90$. Thus, the economic benefit he enjoys - his surplus - is $\$ 30$. Rachael's surplus is $\$ 100-\$ 90=\$ 10$. Thus, the economic surplus in this market is $\$ 40$. $^{3}$

We consider a tax's effect on the total surplus. The government imposes, we'll say, a $\$ 20$ tax on the ticket. The new ticket price is thus $\$ 110, \$ 20$ of which goes to the government and $\$ 90$ of which goes to the train company.

First we consider Justin's situation. He would pay up to $\$ 120$ but now must pay $\$ 110$. His surplus has decreased from $\$ 30$ to $\$ 10$. He is made worse-off by the tax, to the tune of $\$ 20$. However, this tax has generated $\$ 20$ of revenue for the government, which it can transfer to a poor family, or spend on national defense, or simply give back to Justin. Taxing Justin has a redistributive effect - it changes who is made better off by an economic interaction - but it does not affect the efficiency of the economy. The surplus remains \$30. It is just divided differently. 
Second, we look at the tax's effect on Rachael. Her reservation price is $\$ 100$, and she enjoyed a $\$ 10$ surplus before the tax was imposed. Once the tax is imposed, the price of a ticket rises to $\$ 110$. But this exceeds her reservation price. Therefore, Rachael will not buy a ticket, and thereby not enjoy any surplus in this market.

But what about the government? In Justin's case, his surplus loss was offset by the gain in tax revenue. Does something similar happen with Rachael? The answer, unfortunately, is no. The government collects no revenue on market exchanges that do not take place. Unlike the case of Justin, in which the tax only served to change who benefits from his economic activity, taxing Rachael introduces inefficiency into the economy. It reduces the total surplus by $\$ 10$. Rachael is forced out of the market by the tax, losing $\$ 10$ in surplus which is not enjoyed by anyone else. This $\$ 10$ of economic waste is known as the deadweight loss, or excess burden, of the tax.

Let us now turn to a more general, and rigorous, example. Suppose that Jones may work at most 120 hours in a week, and that he earns a wage of $\$ 50$ per hour. Jones thus faces a tradeoff between income and leisure, both of which he desires. For each $\$ 50$ Jones earns, he loses an hour of leisure. For each hour of leisure he enjoys, he gives up $\$ 50$. We may represent the situation facing Jones by the following diagram:

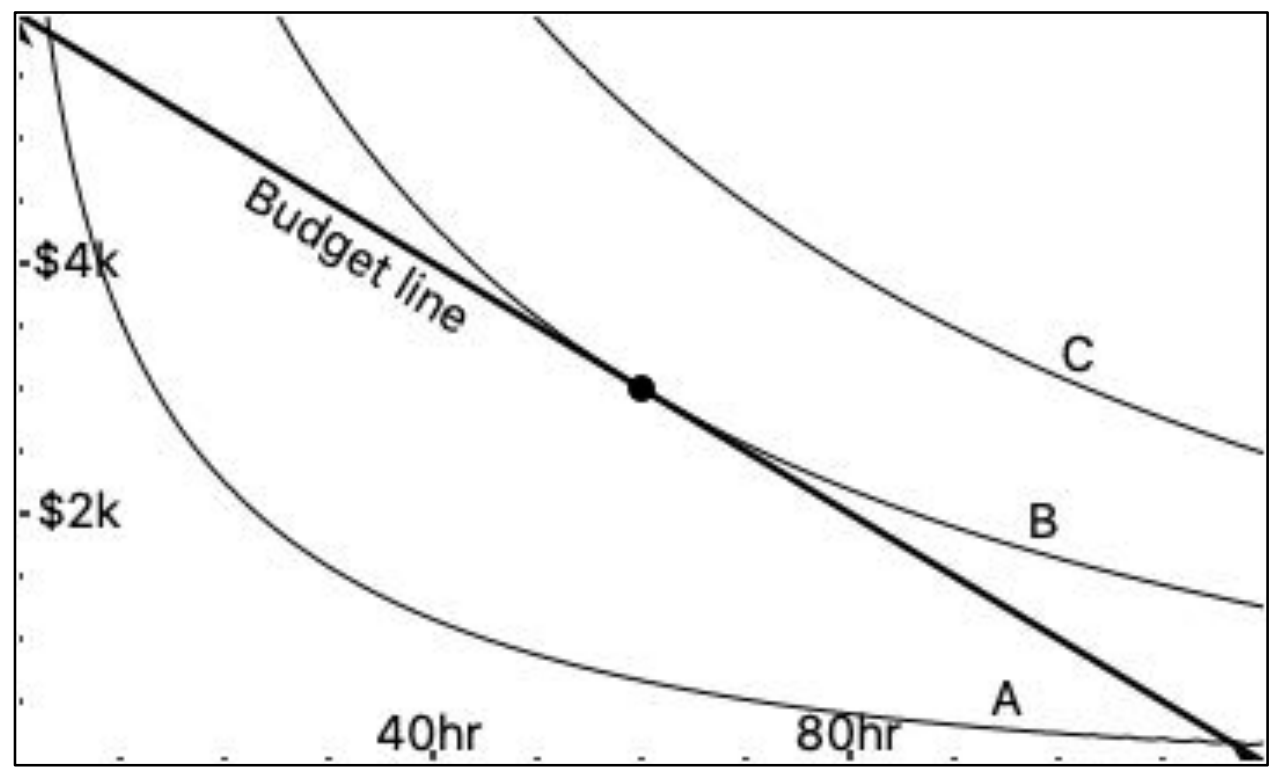

The vertical axis represents Jones's labor choice; the horizontal axis, his leisure choice. At the extremes, Jones may choose to (1) earn $\$ 6,000$ a week (120 hours of work at $\$ 50 /$ hour) with 0 leisure and (2) $\$ 0$ a week with 120 hours of leisure. Jones may also select any point in the segment connecting these two extremes, which we call Jones's budget line.

Which point on the budget line will Jones choose? This depends on his preferences. If he is already rich he will likely favor leisure to labor. If he enjoys his job, that makes work a more attractive prospect. If he is caring for a sick relative, he will want to earn money to pay for her care. And so on. 
How preferences are formed and what, exactly, they are is a complicated matter. The important point is that Jones's preferences, whatever they be, may be represented in the form of indifference curves.

Three of Jones's indifferences curves, $A, B$, and $C$, are shown in Figure X.1. The points on any given indifference curve are combinations of leisure and labor that Jones finds equally desirable. For example, indifference curve $A$ contains the points ( 15 hours leisure, $\$ 2,800)$, (50 hours leisure, \$900) and (80 hours leisure, \$400). Jones is "indifferent" between these three combinations - he will derive the same satisfaction no matter which he chooses.

Indifference curves are typically bowed inward toward the origin, as they are here, to represent the notion that people prefer mixes of goods to extremes. If Jones is not working at all, he may be willing to give up an hour of leisure for very little income. But as he works more and more, his free time becoming scarcer and scarcer (and thereby more and more valuable) he will want more money in return.

The points in any given indifference curve are equally desirable to Jones, but the indifference curves themselves are not. Jones prefers to have more income and more leisure. That is, he would prefer to move to the northeast in Figure X.1. Indifference curve $A$ is the least desirable and $C$ is the most desirable.

However, Jones is constrained by his budget line, which defines all the combinations of labor and leisure that are feasible for Jones. Points on indifference curve $C$ are infeasible; Jones would like to reach them, but he is limited to 120 hours to divide between work and leisure. Points on $A$, on the other hand, are feasible. However, Jones can do better - he can move to the northeast of $A$ until he is on a curve that is tangent to the budget line that touches the budget line at just one point. This point is on indifference curve $B-$ and here Jones must stop; all indifference curves to the northeast of $B$ fail to intersect the budget line, and are, therefore, infeasible.

If we understand Jones's preferences (given by indifference curves) and the constraints he faces when making the labor-leisure decision (his budget line) we may solve for his optimal combination of the two. Here, the optimum is (60 hours leisure, \$3,000). Jones divides his time evenly between work and play. ${ }^{4}$

Now we consider the effect of a tax. Suppose the government levies a 33\% tax on income, which Jones bears. This tax has no effect on Jones if he chooses not to work; he earned (120 hours leisure, \$0) without the tax, and (120 hours leisure, \$0) with the tax.

But what if he chooses to work? The tax means that Jones will receive only two-thirds of the income that he previously did, for any given amount of work. In the extreme case, in which he devotes all his time to work, he earns (0 hours leisure, $\$ 4,000)$ rather than $(0$ hours leisure, $\$ 6,000)$.

More generally, the tax has the effect of flattening out Jones's budget line. Points that were feasible when there was no tax no longer are. Consider the situation facing Jones now (see Figure X.2). 


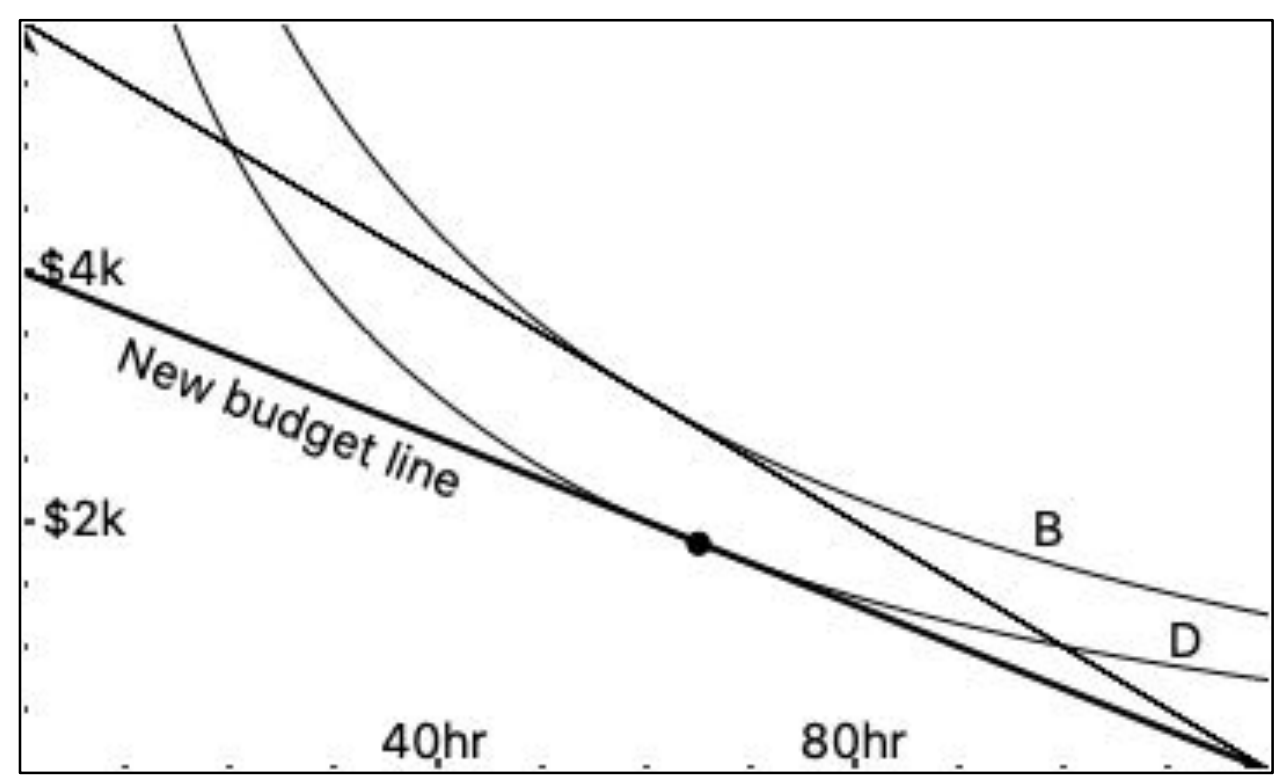

We may see four effects of the tax. The first is the aforementioned flattening of the budget line. If Jones chooses to work at all, then, for any given amount of work, he will earn less than he would if there were no tax. He is now on a budget line that runs from ( 0 hours leisure, $\$ 4,000)$ to $(120$ hours leisure, $\$ 0)$ rather than (0 hours leisure, $\$ 6,000)$ to $(120$ hours leisure, $\$ 0)$.

Second, because the budget line has flattened, indifference curve $B$ is no longer feasible. It is now akin to indifference curve $C$ in Figure X. 1 - out of reach for Jones. So to find Jones's new choice between labor and leisure we do what we did prior to the tax - find the indifference curve that is just tangent to his (new) budget line. This is indifference curve $D$, and it is tangent to the budget line at (65 hours leisure, $\$ 1,800)$. This is the mostpreferred combination of labor and leisure for Jones under the tax.

Third - and this is important - the tax has changed the preferred mixture of labor and leisure for Jones. Prior to the tax he divided his time evenly between the two. Now he trades some labor - five hours' worth - for leisure.

Fourth, the tax has made Jones worse-off. He would prefer to be on indifference curve $B$ rather than $D ; B$ lies to the northeast of $D$. But the tax made that impossible, and so Jones finds himself on the less desirable $D$.

We are now at a point to consider the efficiency effects of the tax. If someone else could be made better-off - as measured in dollars - as Jones was made worse-off by the tax, then there would be no inefficiency. The tax would have a purely distributional effect.

Now, it is important to keep in mind that that alone would not make the tax "good". A perfectly efficient tax that redistributes from virtuous citizens to vicious citizens is bad; an inefficient tax that redistributes from crony bankers to underprivileged children is good. Or so I think. Those are moral judgments which efficiency considerations alone cannot speak to. 
We have established that, under the tax, Jones will work 55 hours and rest 65 hours. He will thus earn, pre-tax, $\$ 50 \times 55 \approx \$ 2,700$. The government will tax away $33 \%$ of this, or $\$ 900$.

We must now determine how much worse off Jones was made by the tax. $\$ 900$ is the difference between his pre-tax income and his post-tax income, and he certainly has been made worse-off by at least that amount. But it does not tell the whole story. It fails to account for the fact that the tax changed the relative prices of labor and leisure for Jones. The tax made labor costlier relative to leisure, inducing Jones to substitute some leisure for labor when, ceteris paribus, he would have preferred to spend those five hours working. This is a real cost, albeit a hidden one, which must be taken into account in our analysis.

To calculate the true cost to Jones, including the cost of his leisure-for-labor substitution, we use a trick. We imagine that the government levies a tax on Jones that does not change the relative prices of labor and leisure; that is, that has the pure effect of making Jones poorer. Such a tax is known as a "lump-sum" tax. In particular, we consider the hypothetical lump-sum tax that harms Jones exactly as much as the actual tax does. This is the lump-sum tax that puts Jones on indifference curve $D$, and is represented in Figure X.3 by a dashed line.

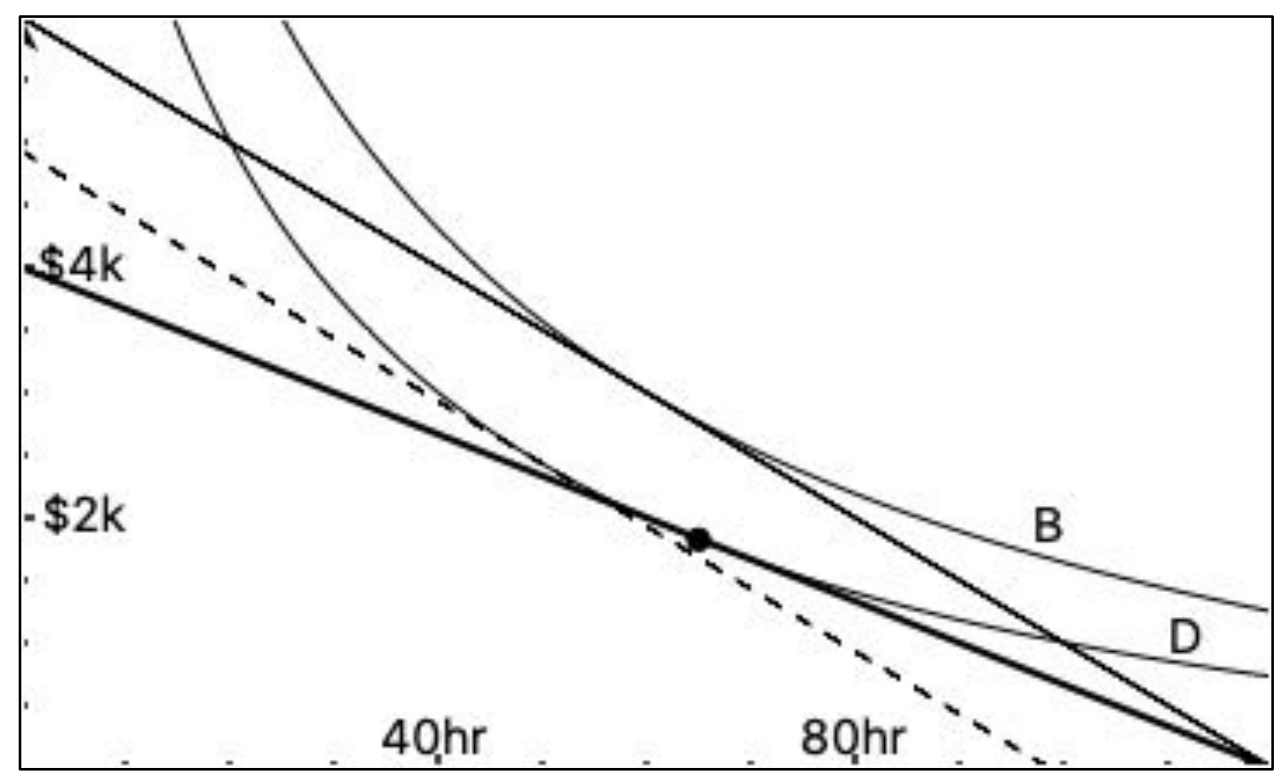

Notice that the amount of revenue this lump-sum tax brings in is independent of Jones's labor/leisure choice. The slope of the original budget line is the same as the slope of the budget line under the lump-sum tax, and so the distance between them is the same for all labor/leisure choices - namely, $\$ 1,100$.

To reiterate: The actual 33\% income tax puts Jones on indifference curve $D$. A lump sum tax of $\$ 1,100$ also puts Jones on indifference curve $D$. From Jones's point-of-view, these taxes are equally bad. However, the actual tax only raises $\$ 900$ in revenue. This difference of $\$ 200$ between the actual tax and the hypothetical lump-sum tax is the deadweight loss of the actual tax. It is the economic waste which this tax creates. 
If the government could levy a lump-sum tax, and not distort Jones's incentive to work, it could raise $\$ 1,100$, which is precisely the amount Jones is harmed by the tax. So there would be no efficiency loss. ${ }^{5}$ The tax would have a pure distributional effect. But only $\$ 900$ is actually raised because of Jones's behavioral response - his substituting of leisure for labor - and so there is inefficiency.

The discussion to this point may seem abstract, and it is. But the abstraction helps illuminate the general nature of the problem. Economists and policymakers struggle with the task of achieving a good distributional outcome - making some citizens better off by making others worse-off - while avoiding introducing too much inefficiency into the economy. As Arthur Okun (1975) memorably put it, redistribution is akin to carrying water in leaky bucket.

A core problem with EPI is the inefficiency that it would introduce into the economy. We could all be given equal shares of the economic pie - no doubt about it - but only if the pie were made very, very small.

Why would EPI be so catastrophic? Because it would eradicate almost any incentive to work. In the above example, the tax diminished Jones's incentive to work but did not destroy it. In the face of the tax, Jones worked five hours less, was made worse-off by $\$ 1,100$, and the government raised $\$ 900$ in revenue.

But under EPI, Jones's income is independent of his labor/leisure choice! If he works 120 hours a week, or 60 hours a week, or not at all, it does not matter - Jones "earns" the same income. So Jones will elect not to work, and the government will not raise any revenue from him.

Jones's choice not to work is a rational one, and it is made by everybody. That is, no one works - no one produces goods or services - and national income is driven toward $\$ 0$. In this way, EPI ensures equal pay for all, and poverty for all.

I have said that EPI would eradicate "almost" any incentive to work, because there would still be reasons for people to choose labor over leisure. I can think of two. (1) is boredom. If hobbies, exercise, spending time with family and friends, the arts, etc., etc., fail to occupy a person, he or she may elect to work despite its having no effect on income. In this case, goods and services will be produced and there will be some income to go around. (2) is altruism. Seeing the deprivations that EPI causes, some people will, nobly, choose to work.

For this reason, EPI's time has not come. For it to be plausible, people's preferences over leisure and labor would have to radically change. To his credit, Carens recognizes (2), arguing that a "logically necessary prerequisite" to an EPI-like system is that "individuals ... believe they have a social duty to earn as much pre-tax net income as they are capable of earning" and that they "place the same relative value on the satisfactions derived from performing their social duty . . . as individuals [in contemporary market economies do]" (1981, p. 25). But such a cultural change should only come to pass if EPI is regarded as a just and desirable economic arrangement in the first place. And it is not. 


\section{The empirical work on justice}

EPI is a bad idea apart from any concerns about inefficiency. That is, even if it were possible to redistribute to provide "equal pay for all" without efficiency loss, we would still reject it - on grounds of justice. Put differently, EPI is bad from a distributional pointof-view.

When I say here that EPI is "bad", I mean that people regard it as bad, which is not exactly the same as saying that it is bad per se. But by my lights, at least, the fact that EPI would be widely rejected - and by people across lines of gender, race, class, and culture - is strong grounds to think that it is morally flawed.

As James Konow, an economist who has done extensive research on people's judgments about justice, puts it, "empirical studies provide almost no support for egalitarianism, understood as equality of outcomes, or for Rawls's difference principle [Rawls 1971]" (2003, p. 1199). The situation is even worse than that for EPI, since "equality of outcomes" is usually understood to mean "everyone who works receives the same income". EPI, which gives everyone the same income no matter if they work or not is much more radical than that.

No: We do not believe that everyone should receive the same income. We believe that factors like effort and contribution matter from the point-of-view of justice. Someone who works hard and makes a significant contribution to our collective economic life should receive more in return than someone who, through indolence, contributes nothing. Some readers will think this obviously true, hardly worth stating, but note that EPI would not allow factors like that - factors that we commonly think matter from the point-of-view of justice - to affect the distribution of income.

Owing to limitations of space I cannot give this matter a full treatment here. (I provide a summary of the empirical literature on justice in Mulligan 2018b.) I do want to note that when economic outcomes are unequal, the reason for the inequality matters critically. If two people have unequal incomes because of unequal opportunity - one was born into wealth and the other, poverty - that inequality of outcome does strike us as unjust. In contrast, economic mobility enables the possibility of just inequality (see, e.g., Shariff et al. 2016; Trump 2020).

Similarly, if two people have unequal incomes for "arbitrary" reasons (e.g. racial discrimination, luck) rather that reasons that have to do with their deservingness (effort, contribution), that offends our sense of justice. But when deserts are unequal, justice requires that incomes be unequal as well.

Our intuitions about desert, and its relevance for economic distribution, are powerful and broadly-shared. Indeed, there is evidence from evolutionary psychology that we are prewired to think that economic outcomes should turn on deserts, and that, perforce, EPI and other egalitarian distributive rules are unjust.

[T] he deservingness heuristic is rooted in evolved cognitive categories designed to detect and represent "cheaters" and "reciprocators," respectively. The crosscultural nature of the present evidence supports the view that these categories 
are not learned. Rather, they are something we as humans naturally come equipped with. (Petersen 2012, p. 12)

Thus I see no reason to believe that EPI will come to be regarded as just in the future.

EPI is a bad idea from the points-of-view of efficiency and distributive justice. It should not be pursued.

\section{References}

Carens, J.H. (1981). Equality, moral incentives, and the market. Chicago: University of Chicago Press.

Konow, J. (2003). Which is the fairest one of all? A positive analysis of justice theories. Journal of Economic Literature, 41(4), 1188-1239.

Mulligan, T. (2018a). Do people deserve their economic rents? Erasmus Journal for Philosophy and Economics, 11(2), 163-190.

Mulligan, T. (2018b). Justice and the meritocratic state. New York: Routledge.

Okun, A. (1975). Equality and efficiency: The big tradeoff. Washington, D.C.: Brookings.

Petersen, M.B. (2012). Social welfare as small-scale help: Evolutionary psychology and the deservingness heuristic. American Journal of Political Science, 56(1), 1-16.

Rawls, J. (1971). A theory of justice. Cambridge, MA: Belknap Press.

Shariff, A.F., Wiwad, D., Aknin, L.B. (2016). Income mobility breeds tolerance for income inequality: Cross-national and experimental evidence. Perspectives on Psychological Science, 11(3), 373-380.

Trump, K.-S. (2020). When and why is economic inequality seen as fair. Current Opinion in Behavioral Sciences, 34(1), 46-51.

\footnotetext{
${ }^{1}$ For this reason, the prevalence of economic rent in contemporary economies is a problem (see Mulligan 2018a).

${ }^{2}$ To my mind, "pay" suggests labor income - i.e. a salary (a fixed amount of money received, regardless of time spent working) or an hourly wage. "Income" includes salaries and wages, but also: capital gains, dividends, interest, government transfers, alimony, etc.

${ }^{3}$ There is also value created on the producer side, as well. The difference between the market price and the company's reservation price - what it would sell a ticket for - is the producer surplus. Total surplus $=$ consumer surplus + producer surplus.

${ }^{4}$ Jones's indifference curves are CES, given by $U(x, y)=\left(x^{0.3}+y^{0.3}\right)^{\frac{1}{0.3}}$.

${ }^{5}$ Lump sum taxes are rare for two reasons. First, it is difficult to design a tax that does not produce some behavioral response. Income taxes disincentivize work; sales taxes disincentivize consumption; and so on. Second, lump sum taxes are typically regarded as unfair because they put a bigger burden on the poor than on the rich. Consider a "poll tax" of $\$ 1,000$. Every citizen must pay this, without exception. This is a lump-sum tax because it cannot be avoided (by working less, or consuming less, or whatever). It is perfectly efficient, but it is (widely regarded as) unfair, since a $\$ 1,000$ tax on someone making $\$ 20,000$ a year is a serious burden, while a $\$ 1,000$ tax on a millionaire is nothing. The most (in)famous example of a lump-sum tax was the "Community Charge" implemented in Great Britain in the late 1980s. It was met with broad opposition, was abolished, and was a prime reason for Margaret Thatcher's resignation in 1990.
} 